\title{
Imagens, políticas e leituras do Arquivo Capanema
}

\author{
Political images and texts from \\ Capanema Archive
}

\author{
Roney Cytrynowicz \\ Doutor em história pela Universidade de São Paulo \\ Rua Ministro Godoy, 171/191 \\ 05015-000 São Paulo - SP Brasil \\ roncytryn@cwaynet.com.br
}

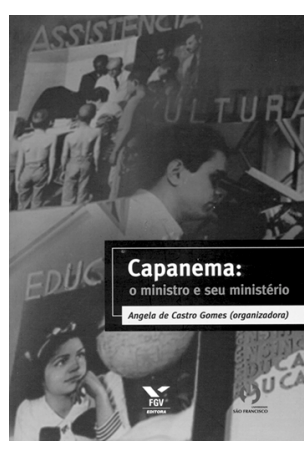

Capanema: o ministro e seu ministério Angela de Castro Gomes (org.)

Rio de Janeiro, Editora FGV, 2000, $276 \mathrm{p}$.
E ntre as personagens políticas do primeiro governo Getúlio Vargas, e mais especificamente do Estado Novo, o ministro da Educação e Saúde entre 1934 e 1945, Gustavo Capanema, é uma figura central na definição ideológica e nas políticas públicas implementadas. Seu ministério tinha, entre outras atribuições, a de formular um projeto cívico-pedagógico para engendrar um "novo homem brasileiro". A reforma do Estado, da sociedade e do homem eram projetos que deveriam caminhar juntos. Educação, saúde e cultura eram pilares para a execução deste ideário. As interpretações mais difundidas sobre as idéias e ações de Capanema têm se apoiado em imagens cuja força, enquanto ícones de uma época, sobrepõem-se às tentativas de uma análise mais apurada. Dois podem ser os fatores determinantes destas interpretações.

Em primeiro lugar, Capanema foi político e intelectual dos mais complexos e de difícil apreensão, mesmo no contexto do ideário conservador. Ele mantinha uma teia de relações pessoais e de colaboradores, que incluía intelectuais de esquerda em pleno Estado Novo. Desta colaboração resultou a obra maior, segundo o ministro, que foi o edifício sede do Ministério da Educação no Rio de Janeiro, considerado um emblema da arquitetura modernista no país. A convivência entre a ditadura e o modernismo tem permanecido sob uma áurea quase enigmática.

Em segundo lugar, a dificuldade de uma interpretação mais precisa sobre o caráter ideológico do Estado Novo: regime autoritário ou ditadura fascista e suas inúmeras nuanças e matizes. Assim, as leituras trabalham com polaridades e dicotomias: por exemplo, uma ala mais ligada ao liberalismo pró-americano versus uma ala mais nacionalista e fascista. Esta dificuldade tem induzido análises centradas nas personagens e em suas políticas, encetando um mosaico cuja resultante é o Estado Novo. Lidar com a diversidade individual dos ministros e de suas ideologias e, ao mesmo tempo, com o que pode ser considerado o núcleo duro ideológico do Estado Novo, permanece como um desafio. O conceito de modernização conservadora, que tem sido utilizado para interpretar muitos outros regimes do período entreguerras na Europa, poderia ser uma chave importante, como já foi sugerido em Tempos de Capanema, organizado em 1984 por Simon Schwartzman, Helena Maria Bousquet Bomeny e Vanda Maria Ribeiro Costa, volume escrito a partir de uma primeira leitura do 
acervo Capanema (duzentos mil documentos), legado pelo próprio ministro ao CPDOC da Fundação Getúlio Vargas do Rio de Janeiro.

Capanema: o ministro e seu ministério, organizado por Angela de Castro Gomes, composto de nove artigos baseados neste acervo, é uma segunda leitura da ação do ministro. O livro, editado no centenário de nascimento de Capanema (1900-85), expõe e valoriza o trabalho com as fontes primárias e elabora a própria lógica de organização do acervo, desvendando sua montagem e organização (tema do artigo de Priscila Fraiz, que o analisa como um projeto autobiográfico). A coletânea é o resultado de várias abordagens e olhares sobre as idéias e ações de Capanema, sobre as dicotomias e contradições do ministério, oferecendo uma visão interna à lógica de ação do ministro, mas nem sempre propondo uma interpretação historiográfica de sua ação política (como a discussão do conceito de modernização conservadora ou de fascismo). Para Daryle Williams, em seu artigo sobre a política cultural do ministro, Capanema oscilou entre o corporativismo católico, o liberalismo reformado e o fascismo. Um dado interessante é que foi justamente o seu ministério que foi oferecido em negociação aos integralistas como forma de ganhar sua adesão ao Estado Novo, o que mostra, talvez, o lugar ideológico do ministério na visão de Vargas.

Um das marcas principais que emerge da leitura dos artigos é a análise da ação política que inaugurou políticas públicas de abrangência nacional, como na saúde e na educação, em um Estado que estava se organizando enquanto estrutura política e burocrática nacional. No tema da saúde e da educação, por exemplo, Gilberto Hochman e Cristina Fonseca mostram, ao analisar a I Conferência Nacional de Saúde de 1941, como, tendo instituído uma política de saúde pública entre 1934 e 1945, "sob os auspícios da ideologia de construção de um renovado homem brasileiro, sadio e educado, e de uma política autoritária, uniformizada e centralista, realizavam-se conferências oficiais que, não obstante os limites impostos pelos seus regimentos e sua organização, possibilitavam um debate ampliado sobre os rumos das políticas de educação e saúde, inclusive com críticas ao governo". Para os autores, no Estado pós anos 1930 observase a organização, profissionalização, despolitização, burocratização e centralização das políticas (que possibilitaram que se formasse uma geração treinada e voltada para o serviço público) em contraste com a perspectiva campanhista e voluntarista, fragmentada e politizada das décadas de 1910 e 1920.

A frase de Hochman e Fonseca poderia ser a síntese da imagem e das políticas de Gustavo Capanema. Uma ideologia autoritária (ou fascista, se lembrarmos seu papel na criação das milícias em Minas Gerais) convivia com políticas "modernas" (no sentido de modernização conservadora) e, paradoxalmente, com a possibilidade de debate. Estas convivências e paradoxos são também a marca da teia de relações pessoais de Capanema, levantada e analisada pelo ensaio de Angela de Castro Gomes, para quem um dos objetivos da coletânea é justamente "a reflexão sobre as ambigüidades de figuras políticas como Capanema e Vargas e de um período autoritário e cheio de iniciativas na área social como foi o Estado Novo".

Cabe destacar a originalidade da metodologia utilizada por Angela de Castro Gomes em seu ensaio baseado na correspondência do ministro, 
ao definir as suas categorias de análise, entendendo a correspondência privada do ministro como "lugar de sociabilidade" de intelectuais nos anos 1930 e 1940. A autora elabora uma interpretação consistente sobre as formas de negociação e cooptação utilizadas pelo ministro, que possibilitou que ele mantivesse uma teia de relações de amplo espectro político no interior de um regime ditatorial.

André Luiz Vieira Campos estuda a fundação do Serviço Especial de Saúde Pública, que surgiu atrelado à política externa dos Estados Unidos para a América Latina em função da Segunda Guerra Mundial e que foi, após o final da guerra, a "principal responsável pela organização da infraestrutura sanitária da maioria dos estados brasileiros, criando assim no Brasil um modelo de saúde pública inspirado no modelo norte-americano dos centros de saúde". O auge deste modelo deu-se nos anos 1950, tornando-se o principal paradigma da formulação primeira de uma política de saúde pública no Brasil, diferentemente de um modelo de saúde curativa que tinha o hospital como centro e que tornou a medicina um negócio privado. $\mathrm{O}$ artigo mostra, portanto, as repercussões da política de Capanema muito além do Estado Novo.

Artigos como os de Mauricio Lissovsky e Paulo Sérgio Moraes de Sá analisam o tortuoso caminho para a construção do edifício do ministério e as controvérsias em torno do modernismo. Uma análise comparativa poderia, no entanto, ampliar o debate do modernismo (também na literatura, na música e nas artes plásticas) no país com sua moldura nacionalista e, no caso de São Paulo, atrelado às oligarquias da cafeicultura (desde os anos 1920). Pode haver, claro, diferenças importantes entre a inserção social e política do movimento no Rio de Janeiro nos anos 1930 e 1940 e em São Paulo nos anos 1920, mas seria interessante não aceitar previamente a visão dos agentes na época, como a de Lúcio Costa e, dessa forma, analisar criticamente a convivência entre Estado Novo e modernismo, entendido como projeto cultural e político mais amplo do que a discussão na arquitetura. $\mathrm{O}$ apelo da formulação política forte por parte do Estado varguista é um dado importante, mas é preciso questionálo especialmente no sentido de ir além da memória (também da própria historiografia) dos eventos chamados de "revolução" de 1930 e Estado "Novo" e que foi construída a partir do próprio governo Vargas (como mostra Aline Lopes de Lacerda).

O volume tem também artigos de Aline Lopes de Lacerda, sobre o uso da fotografia pelo Estado Novo, e de José Silvério Baia Horta e Cynthia Pereira de Souza, sobre educação e juventude e sobre infância. O debate que tem revalorizado os anos anteriores à década de 1930 - tida como marco da organização do Estado - é complexo e necessário. No caso das políticas de educação, infância e juventude, certamente encontra-se, pelo menos em São Paulo, uma preocupação oficial que antecede os debates e políticas dos anos 1930 e seria interessante aprofundar mais o que é específico ou não daqueles anos e do Estado Novo.

Os anos do primeiro governo Vargas e do Estado Novo possuem uma bibliografia densa e heterogênea. Alguns autores cruciais não são debatidos no livro, como, por exemplo, Alcir Lenharo, Boris Fausto e Sergio Miceli, o que acaba privilegiando uma perspectiva sem mediações historiográficas externas ao trabalho com as fontes primárias. O diálogo 
com o precursor volume Tempos de Capanema, anteriormente, citado teria sido muito proveitoso, já que os dois volumes apresentam recortes com preocupações e abordagens diferentes e produzem interpretações divergentes.

No geral, com as naturais diferenças de uma coletânea, o volume dirigido por Angela de Castro Gomes é bem organizado e equilibrado em seus temas e abordagens, permitindo que o pesquisador e o leitor interessado tenham um amplo painel não apenas das idéias e das políticas do ministro Gustavo Capanema, como também das possibilidades de pesquisa no seu acervo e do próprio ofício do historiador e do cientista social no trabalho com as fontes.

Sua contribuição é importante para o estudo e a compreensão do período e sinaliza a necessidade de continuar a pesquisa e aprofundar as interpretações, agregando análises comparativas. Especialmente porque continuamos a viver muitos dos debates e dilemas colocados naquele período, mesmo que atenuados de sua carga ideológica mais explícita, principalmente no que se refere à natureza e às políticas do Estado brasileiro. Às ciências humanas cabe o desafio de afiar as ferramentas como é feito neste volume - para ampliar este debate, trazendo a gama de opções com que ele foi travado nas décadas de 1930 e 1940, durante o primeiro regime Vargas. 